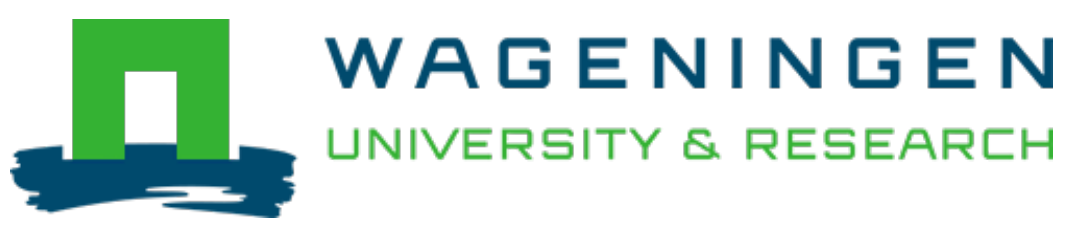

\title{
Agent-Based Simulation of Policies to Reconnect a City and the Countryside
}

Advances in Social Simulation - Proceedings of the 15th Social Simulation Conference, 2019

Verwaart, Tim; Wassenaer, Lan; Hofstede, Gert J.

https://doi.org/10.1007/978-3-030-61503-1_10

This article is made publicly available in the institutional repository of Wageningen University and Research, under the terms of article $25 \mathrm{fa}$ of the Dutch Copyright Act, also known as the Amendment Taverne. This has been done with explicit consent by the author.

Article $25 \mathrm{fa}$ states that the author of a short scientific work funded either wholly or partially by Dutch public funds is entitled to make that work publicly available for no consideration following a reasonable period of time after the work was first published, provided that clear reference is made to the source of the first publication of the work.

This publication is distributed under The Association of Universities in the Netherlands (VSNU) 'Article $25 \mathrm{fa}$ implementation' project. In this project research outputs of researchers employed by Dutch Universities that comply with the legal requirements of Article $25 \mathrm{fa}$ of the Dutch Copyright Act are distributed online and free of cost or other barriers in institutional repositories. Research outputs are distributed six months after their first online publication in the original published version and with proper attribution to the source of the original publication.

You are permitted to download and use the publication for personal purposes. All rights remain with the author(s) and / or copyright owner(s) of this work. Any use of the publication or parts of it other than authorised under article $25 \mathrm{fa}$ of the Dutch Copyright act is prohibited. Wageningen University \& Research and the author(s) of this publication shall not be held responsible or liable for any damages resulting from your (re)use of this publication.

For questions regarding the public availability of this article please contact openscience.library@wur.nl 


\title{
Chapter 10 \\ Agent-Based Simulation of Policies to Reconnect a City and the Countryside
}

\author{
Tim Verwaart, Lan van Wassenaer, and Gert Jan Hofstede
}

\begin{abstract}
An agent-based model was created to capture the spatio-temporal dynamics of the economy at the level of a Dutch province. After 1945, Noord-Brabant has been subject to an active program of economic development through the stimulation of pig husbandry. This has had far-reaching effects on its economy, landscape, and environment. The simulation is at institutional level, with typical stakeholder groups, lobbies, and political parties playing a role in determining policies that in turn determine economic, spatial and ecological outcomes. It allows to experiment with alternative scenarios based on two political dimensions: local versus global issues, and economic versus social responsibility priorities. The paper describes the model and presents examples of outcomes showing disconnect and reconnect. The model shows very strong sensitivity to political context. It can serve as a reference model for other cases where "artificial institutional economy" is attempted.
\end{abstract}

Keywords institutions $\cdot$ Regional policy $\cdot$ Livestock farming $\cdot$ Livelihood

\section{Introduction}

In the past centuries, industrialization has changed the way food systems are coordinated. Thanks to great advancements in logistics, local food systems are increasingly linked to global food systems. Cities are no longer dependent on their 'country-sides' for food system services. One of the consequences is a disconnect between cities and the countryside. This poses a threat to the sustainability and resilience of the food system at different levels [1].

Local food systems used to have tight feedback loops. Consumers and producers, as well as externalities, were closely linked within local food systems. These direct

T. Verwaart · L. van Wassenaer · G. J. Hofstede Wageningen UR, Wageningen, The Netherlands

G. J. Hofstede $(\bowtie)$

North-West University, Mahikeng, South Africa

e-mail: gertjan.hofstede@wur.nl

(C) The Author(s), under exclusive license to Springer Nature Switzerland AG 2021

P. Ahrweiler and M. Neumann (eds.), Advances in Social Simulation,

Springer Proceedings in Complexity,

https://doi.org/10.1007/978-3-030-61503-1_10 
feedback loops were fundamental to the resilience of the food system in coping with perturbations from nature and the market. With globalization, more direct feedback loops need to be replaced by other institutionalized ways of feedback arrangements to avoid disconnects and enhance the resilience.

Based on Cumming et al. [1], Termeer et al. [6] elaborated on the importance of rules and traditions to maintain ecosystem services and connects between urban and agricultural systems. Their analytical framework seeks to explain the dynamic processes of institutional change, the strategies and interactions of powerful players in the system and their embeddedness in political systems. This framework was used to re-examine a historical case: the intensification of the livestock sector in Southern Netherlands (the Province Noord-Brabant) from the 19th century until today. Their conception of institutions centers on two aspects: rules and power. Institutions can be seen as formal and informal rules that shape patterns of political, economic and social interactions, without determining them. Such rules guide the behavior of governments, markets and civil society actors operating at multiple scales. The importance of power is due to the fact that rules are often results of negotiations between powerful and less power actors. While these two aspects greatly contribute to conceptual understanding of the dynamics of the livestock sector, the institutional mechanisms remain rather abstract and elusive due to the complexity of the situation and the large amount of stakeholders involved. This makes it difficult to conduce policy analysis on alternative institutional arrangements.

Inspired by the theoretical framework and historical analysis developed by Termeer et al. [6], this paper describes an agent-based simulation model that aims to operationalize the concepts and mechanisms from the bottom up, and enable policy analysis. In particular, the paper seeks to build an ontology of institutional mechanisms by developing reference models for actors and their interactions. The ontology aims to be generic across cases, with Noord-Brabant as the example and for calibration.

In the sections that follow, the model is first described in detail, followed by selected results that illustrate possible outcomes of different policy intervention. The paper concludes on the applicability, limitation and future developments of the model developed.

\section{The Agent-Based Simulation Model}

This section describes the simulation, following the revised ODD protocol [3]. The simulation is programmed in NetLogo. Source code, data, and sensitivity analysis are available from the CoMSES OpenABM model library under the title "Policies to reconnect a city and the countryside" (https://www.comses.net/).

Purpose The simulation supports regional policy making with respect to the relation between city and countryside, in a democratic polity. To this end it enables the exploration of potential consequences of alternative interventions, and counterfac- 
tuals, i.e., situations that could have emerged under different courses of events. As an example a region is simulated where a rapidly expanding high-tech industry in the city and an intensive livestock industry in the countryside compete for space for housing, farming, and leisure. Tensions arise between the traditionally powerful agricultural sector and environmental and animal-welfare movements and the high-tech industry. The latter require clean production locations and a healthy, safe, attractive, living environment in order to recruit and sustain highly qualified staff.

The purpose of the simulation is to make clear how regional policies and material, monetary, migration, and information flows can affect each other under pressure from lobbies, public opinion, and national and EU-policies.

Entities, state variables, and scales Figure 10.1 depicts the entities represented in the simulation. Several types of agents act in an environment comprising plots with different types of land use. Three sets of plots represent urban, countryside, and village areas. One of the urban plots represents the city center, where offices are located. The other plots can be used for housing or farming. Maximal population density and cost of living depend on the land use type. An urban plot can typically house up to 25 individual households, a village 10, and a countryside plot only one. The countryside typically has the highest cost of living; villages are the cheapest. Livestock keeping can be restricted to particular areas in the countryside. Furthermore, the air around livestock farms can be polluted and health hazards may be effective in case of disease outbreaks.

Households are the main actors in the simulation, where a household stands for an individual with some economic activity and the household depending on that activity. Households are assumed to have a single economic activity or inactivity. They may either be farmers or workers in the agri-industry, or high-tech workers, or be unemployed or disabled. The economic activity generates incoming and outgoing monetary flows, resulting in a cash balance. A farmers' income results from exploitation of a production capacity; the others receive a salary or some form of support. Farmers generate flows of manure, bad air, and, in case of disease outbreaks, infection risk. Other individuals can be affected by these flows. Some country dwellers in financial trouble engage (irreversibly) in criminal activities, such as growing Indian hemp or facilitating drug-labs.

Individuals' actions are assumed to be governed by norms that depend on reference group memberships (Table 10.1). A reference group is here defined as a group who are expected to act according to a set of common rules (norms). Membership of some reference groups can be chosen by individuals if the norms correspond with their opinions, some can be left if the norms no longer correspond. Membership of some groups is forced by circumstances, such as unemployed and disabled. Membership can be bound by conditions for joining, leaving, or remaining; for instance a farmer has to leave the reference group farmers when bankrupt. Some groups are mutually exclusive, such as farmers and unemployed. Public administration serves as a reference group of which all individuals are members. Its norms apply to all individuals. Emigration is the only way to escape from it. 


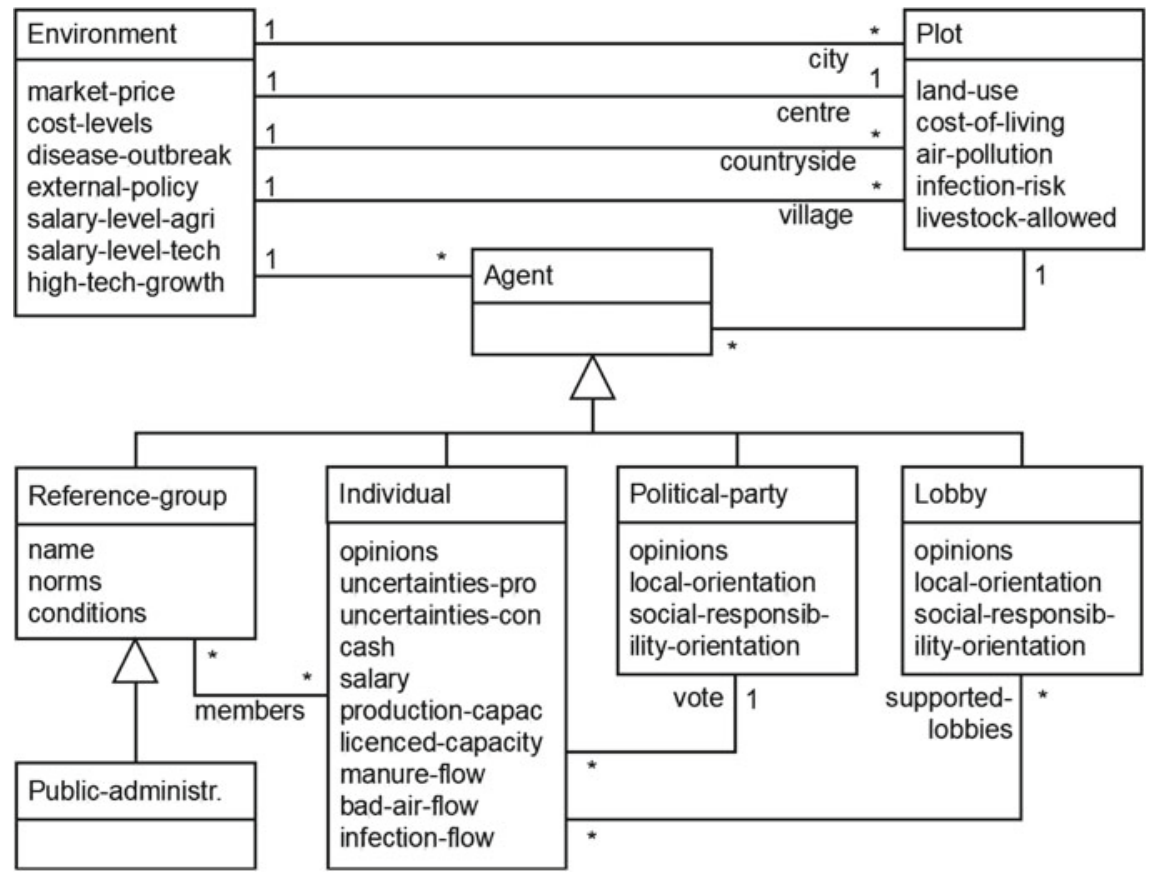

Fig. 10.1 Class diagram representing the entities in the simulation

Table 10.1 Lists of reference groups, lobbies, and norms currently represented

\begin{tabular}{l|l|l}
\hline Reference groups & Lobbies & Norms \\
\hline Farmers & Livestock-lobby & Invest in livestock farming \\
\hline Countryside-criminals & High-tech-lobby & Care for the local environment \\
\hline Agri-workers & Global-responsibility-lobby & $\begin{array}{l}\text { Care for the global } \\
\text { environment }\end{array}$ \\
\hline High-tech-workers & Local-responsibility-lobby & Foster agri sector \\
\hline Unemployed & & Foster high-tech industry \\
\hline Villagers & & Work in agri industry \\
\hline Urbanites & & Work in high-tech industry \\
\hline Commuters & & Live in the countryside \\
\hline Patients & & Live in a village \\
\hline Locally-involved & & Live in the city \\
\hline Globally-involved & & Licence required for livestock \\
\hline Public-administration & & $\begin{array}{l}\text { No livestock near populated } \\
\text { areas }\end{array}$ \\
\hline & & Freeze production capacity \\
\hline & & No more licences \\
\hline & & Engage in criminal activities \\
\hline
\end{tabular}


Political parties and lobbies participate in the formulation of norms to be applied by the public administration, such as conditions for farming licenses. Individuals vote for political parties in periodic elections. An individual's vote is assumed to be based on the distance between its opinions vector and those of the parties (the "party programs"). Public administration implements the norms for which a sufficiently positive opinion exists among the parties, weighed by the number of votes. Between elections, party programs may change. Parties are characterized by two dimensions: an orientation towards local problems versus global problems, and an orientation towards economic issues versus social responsibility issues. Lobbies (see Table 10.1) try and affect the party programs. Their success is assumed to depend on the extent to which their orientations match and on the economic relevance of their supporters, which is measured as the sum of salaries plus farmers' cash flows of individuals.

Furthermore, lobbies try and affect the public opinion. The simulation applies mechanisms of opinion dynamics [4]. The opinions concern norms (see Table 10.1 for a list of currently implemented norms). Opinions express a positive or negative stance regarding a particular norm, which can be affected by communications from lobbies or discussions with other reference group members. The extent to which an opinion can be affected depends on an individual's uncertainty about the issue. Uncertainty may be aroused by information flows and events like disease outbreaks. These mechanisms are further discussed under "Submodels". With respect to lobbies, it must be noted that they have another role than the reference groups: reference groups set norms for their members; lobbies try and set norms for others.

The simulation proceeds in an abstract world of 33 by 33 patches, with initially mostly countryside patches where farmers dwell and produce pigs, a village area inhabited by agri-industry workers, and a city populated by workers in the high-tech industry. The industries are assumed to not only comprise the core activities, but also input supply, processing, transport, and services such as finance, accounting, veterinary, construction, maintenance, legal, catering, etc. The simulation typically spans a period of fifty years, in time steps of one year.

Process overview and scheduling The simulation starts with initialization by assigning plots to city, countryside, and village areas, and populating the plots: reference groups, lobbies, political parties, and public administration in the city center, hightech workers in the other city plots, farmers in the countryside, and agri-workers in the village areas. Then the simulation runs for a number of time steps, each representing a year. Figure 10.2 depicts the process flow per step.

External influences are generated: the market price for fattened pigs is generated at random between a lower and upper bound set in the user interface. The production cost is increased by a percentage due to national and international environmental and animal welfare policies and quality restrictions. Disease outbreaks are generated with a frequency set in the user interface.

Individuals generate flows. They spend a particular cost of living, depending on the type of plot they live on. Farmers produce pigs, manure, bad air, and infection risks (the latter in case of a disease outbreak), and sell pigs. When they have sufficient capital and licenses, they invest in capacity extension. If they have capital 


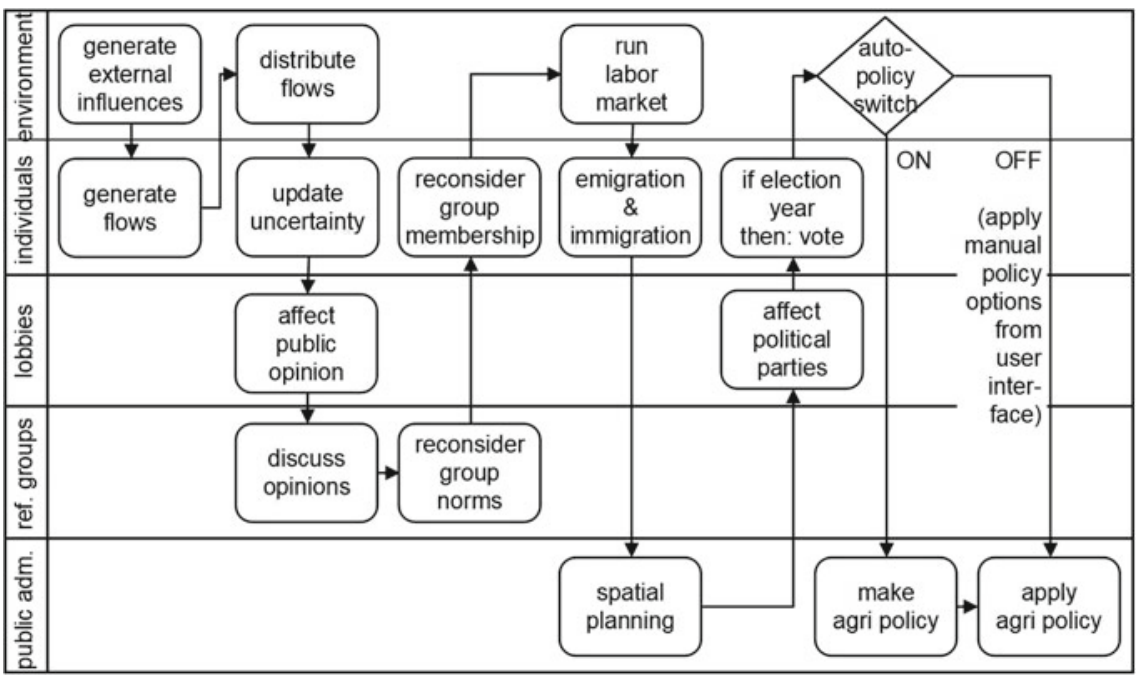

Fig. 10.2 Process flow in a single, one year, time step

but no license, they apply for it. Workers in high-tech and agri industry receive a salary. Unemployed and patients receive support for the cost of living. Some farmers complete their incomes by facilitating criminal activities.

Flows are distributed through the environment. Manure is accumulated in the environment. Bad air and infection risk spread locally and can cause serious nuisance or disable people. Data on economic growth, population, production, employment, environment, and disease outbreaks become available to all agents.

Flows and aspects of their current situation can affect individuals' uncertainties about their current opinions. For instance, for a farmer a high profit is desirable, but great manure flows may reinforce others' doubts about farming. Bad air may make people uncertain whether they are living in the right place or not. Disease outbreaks may make the public opinion susceptible to campaigns to restrict farming.

Lobbies try and affect the public opinion through communication campaigns, addressing particular uncertainties. Individuals discuss opinions in their reference groups, which generally leads to convergence of opinions. As a result of opinion shifts, a group's norms may be adapted.

Individuals may reconsider their reference group memberships and leave or join groups. These decisions are governed by opinions about the norms, and by membership conditions. Some changes are voluntary; for instance, high-tech workers who want to live in the countryside can leave the urbanites and join the commuters, if they have sufficient capital and a plot is available. They can move back if they don't like it anymore. Changes can also be forced, e.g., farmers who no longer have sufficient cash or licenses must quit, sell their farm, become villagers or urbanites, and join the unemployed. 
In the labor market, employment in the agri-industry depends on total pig production in the region; employment in the high-tech industry is assumed to depend on an externally determined growth, which is generated at random within some bounds in each time step. Tight conditions in the labor market induce immigration. On the other hand, long-term unemployment stimulates individuals to emigrate from the region.

Public administration can extend city and village areas in case of population growth. To this end, country dwellers on the edges are expropriated. Depending on current agricultural policy, new licenses may granted to expropriated farmers, or they may just be bought out.

Lobbies try and affect political parties' opinions, which are voiced in the party programs. Lobbies can affect policy not only through affecting public opinion before elections. Lobbying continues between election years. The policies implemented by public administration depend on the parties' opinions, weighed by the votes from the recent election. When the parties' opinions change under the influence of lobbies, new policies can be implemented.

Examples of policies directed to livestock farming are investment support (to increase livestock production) and binding livestock keeping by licensing (to achieve the opposite). Licensing enables freezing the total production capacity in the region, reducing total livestock by restricted licensing and buy-out, or restricting livestock farming to particular areas, or combinations of these policies.

Design concepts Basic principles of the model are opinion dynamics [4] and rulefollowing decision-making [5] by individuals and a public administration under a democratic polity, which can constrain farmers' decisions through licensing and buyout. Land use planning by the public administration prioritizes other industries and housing over agricultural land use and expropriates country dwellers when space is required. The modeled entities and processes are based on historical research on the region and expert data on current politics.

Emergence: Potentially emerging phenomena are the growth or collapse of economic sectors, urbanization, pressure on the environment, public support for particular policies, consequences of policies, and the effects from lobbies and arousing events on policies.

Adaptation: Individuals may adapt their opinions and change their reference group memberships, and their support for lobbies and political parties. Public policy may change under pressure from lobbies and public opinion.

Objectives: The only actors pursuing objectives are the lobbies. Other actors are affected by them, but are modeled as rule-following decision makers.

Learning: Based on experience and information, individuals can (based on changed opinions or forced by circumstances) change their reference group memberships and then apply different decision rules. However, they simply follow new rules and do not make or use Predictions.

Sensing: Individuals can sense the condition of their environment, can receive information flows reporting on consequences of others' actions, and are aware of others' opinions. 

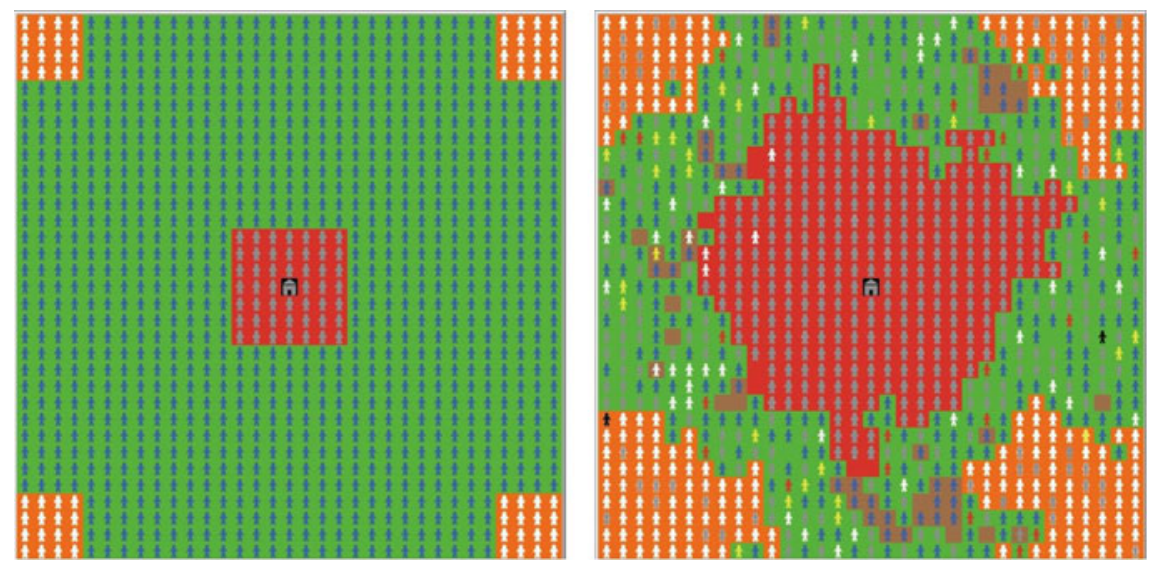

Fig. 10.3 Examples of the simulated world view, after initialization and a (counterfactual) situation 50 years later, illustrating the effect of urbanization (area color legend: green — countryside; redcity; orange—village; brown — high pressure on the environment)

Interaction: Interactions between individuals in reference groups, between lobbies and individuals and between lobbies and political parties are based on opinion dynamics [4]. Individuals' uncertainty (susceptibility to others' opinions) depends on personal experience, uncertainty arousing events, and information on developments in their environment.

Stochasticity: Variation of simulation outcomes results from random fluctuations in pig price, high-tech industry growth, disease outbreaks and, to a lesser extent, randomly generated expropriation decisions, encounters during opinion exchange, opportunities to move, and the distribution of initialized agent traits (production capacity, salary).

Collectives: Agents are members of reference groups, in which they maintain common norms and discuss opinions.

Observation: The main question is: will the intensive livestock industry collapse or survive? Main observables in this respect are the number of farms, total annual pig production, and employment in the livestock complex. An additional question is: if the livestock sector survives, is that possible without hindering the evolution of the high-tech industry? Observables for this purpose are high-tech employment and emigration of high-tech staff. Furthermore, it is useful to observe the strengths of the different lobbies, general indicators such as population growth and employment, and urbanization (see Fig. 10.3; the red area is the city).

Initialization and input data The simulation is initialized as a world of 33 by 33 patches. Reference groups, lobbies, political parties, and public administration are located on the central patch (see Fig. 10.3). Around the patch a city is populated with 25 households of high-tech workers per patch, with a salary generated at random around the average, set in the user interface. The countryside is populated with one farm household per patch, with a production capacity generated at random around 
Table 10.2 Inputs and other parameters with their default settings

\begin{tabular}{|c|c|c|c|c|c|}
\hline Parameter & Value & Unit & Parameter & Value & Unit \\
\hline $\begin{array}{l}\text { Simulation- } \\
\text { time }\end{array}$ & 50 & $\mathrm{y}$ & $\begin{array}{l}\text { Country-cost- } \\
\text { of-living }\end{array}$ & 30000 & $/ y$ \\
\hline $\begin{array}{l}\text { Mean-initial- } \\
\text { capacity }\end{array}$ & 500 & pigs/y & $\begin{array}{l}\text { City-cost-of- } \\
\text { living }\end{array}$ & 25000 & $/ y$ \\
\hline $\begin{array}{l}\text { Price-upper- } \\
\text { bound }\end{array}$ & 130 & $/$ pig & $\begin{array}{l}\text { Village-cost- } \\
\text { of-living }\end{array}$ & 20000 & $/ y$ \\
\hline $\begin{array}{l}\text { Price-lower- } \\
\text { bound }\end{array}$ & 110 & $/$ pig & $\begin{array}{l}\text { Farm-estate- } \\
\text { value }\end{array}$ & 1000000 & \\
\hline $\begin{array}{l}\text { Initial- } \\
\text { production- } \\
\cos \end{array}$ & 70 & $/$ pig & $\begin{array}{l}\text { Opinion- } \\
\text { dynamics-mu }\end{array}$ & 0.2 & \\
\hline $\begin{array}{l}\text { External- } \\
\text { policy-effect }\end{array}$ & 0.042 & $/ y$ & $\begin{array}{l}\text { Initial- } \\
\text { uncertainty- } \\
\text { min }\end{array}$ & 0.4 & \\
\hline $\begin{array}{l}\text { Capacity- } \\
\text { investment- } \\
\text { cost }\end{array}$ & 200 & & $\begin{array}{l}\text { Initial- } \\
\text { uncertainty- } \\
\max \end{array}$ & 0.6 & \\
\hline $\begin{array}{l}\text { Outbreak- } \\
\text { frequency }\end{array}$ & 0.04 & $/ y$ & $\begin{array}{l}\text { Interaction- } \\
\text { partners }\end{array}$ & 2 & $/ \mathrm{y}$ \\
\hline $\begin{array}{l}\text { Criminal- } \\
\text { susceptibility }\end{array}$ & 0 & & $\begin{array}{l}\text { Norm- } \\
\text { adoption- } \\
\text { threshold }\end{array}$ & 0.83 & \\
\hline $\begin{array}{l}\text { Mean-salary- } \\
\text { agri }\end{array}$ & 40000 & $/ y$ & $\begin{array}{l}\text { Policy- } \\
\text { threshold }\end{array}$ & 0.5 & \\
\hline $\begin{array}{l}\text { Agri- } \\
\text { complex- } \\
\text { employment }\end{array}$ & 0.001 & $/ \mathrm{pig} / \mathrm{y}$ & $\begin{array}{l}\text { Lobby- } \\
\text { effectiveness }\end{array}$ & 0.3 & \\
\hline $\begin{array}{l}\text { Mean-salary- } \\
\text { tech }\end{array}$ & 30000 & $/ y$ & \begin{tabular}{|l} 
Election- \\
period
\end{tabular} & 4 & $\mathrm{y}$ \\
\hline $\begin{array}{l}\text { Tech-industry- } \\
\text { growth }\end{array}$ & 3.3 & $\% / y$ & $\begin{array}{l}\text { Unemployed- } \\
\text { emigration- } \\
\text { factor }\end{array}$ & 0.1 & $/ y$ \\
\hline Bad-air-limit & 30000 & pigs/y & & & \\
\hline
\end{tabular}

the average, set in the user interface. Village areas are populated with 10 agri-sector workers per patch, with a salary generated at random around the average, set in the user interface.

Further inputs and parameters (see Table 10.2) can all be set in the user interface. The inputs are calibrated against data obtained from statistics and experts on the pig production evolution in Noord-Brabant and the Netherlands in general. Details and sensitivity analysis are available on CoMSES/OpenABM.

Submodels The rules that the individuals follow are based on the norms of reference groups to which they belong. Individuals have opinions on the norms of their own 
reference groups and those of other groups. Opinions on norms are represented as a vector $\mathbf{x}$; each element $x_{i}$ represents an opinion on a particular norm as a real number on a scale from 0 (negative opinion) to 1 (positive opinion). Individual's opinions are initialized $x_{i}=1$ for the norms of their reference groups, $x_{i}=0.5$ (indifferent) for other norms. Lobbies' opinions are initialized as $x_{i}=1$ for the norms they promote, $x_{i}=0$ for the norms they oppose, $x_{i}=0.5$ for the other norms. For political parties, all norms are initialized as $x_{i}=0.5$.

Lobbies do not change their opinions, but affect those of political parties and individuals. Their effect on opinions in political party programs is computed as:

$$
x_{i}(t+1)=x_{i}(t)+\epsilon \sigma \delta\left(x_{i}^{\prime}-x_{i}(t)\right)
$$

where $x_{i}^{\prime}$ stands for a lobby's opinion on norm $i$ and lobby effectiveness $\epsilon$ is a global parameter set in the user interface; $0<\epsilon<1$. A lobby's strength $\sigma$ is computed as the sum of salaries plus farmers' cash flows of individuals who support the lobby, divided by the sum of salaries plus farmers' cash flows of all individuals. The ideological distance $\delta=\left(\left|\lambda_{\mathrm{p}}-\lambda_{\mathrm{l}}\right|+\left|\rho_{\mathrm{p}}-\rho_{\mathrm{l}}\right|\right) / 2$, where $\lambda_{\mathrm{p}}, \lambda_{\mathrm{l}}, \rho_{\mathrm{p}}$, and $\rho_{\mathrm{l}}$ stand for local versus global and social responsibility versus economy orientations of party and lobby, all as real variables in $[0 \ldots 1]$.

An individual's opinion can be affected by another agent, such as a lobby, according to the individual's left-hand $\left(y_{i}\right)$ and right-hand $\left(z_{i}\right)$ uncertainties:

$$
x_{i}(t+1)= \begin{cases}x_{i}(t)+\mu\left(x_{i}^{\prime}(t)-x_{i}(t)\right), & \text { if }-y_{i} \leq x_{i}^{\prime}(t)-x_{i}(t) \leq z_{i} \\ x_{i}(t), & \text { otherwise, }\end{cases}
$$

where $\mu$ is the opinion dynamics convergence parameter, $0 \leq \mu \leq 0.5$.

Individuals discuss opinions in their reference groups. The number of interactions they seek per time step in each of their reference groups is set in the user interface. When two members of a reference group meet and discuss norm, both update their opinions according to Eq. 10.2.

The elements of uncertainty vectors $\mathbf{y}$ and $\mathbf{z}$ are initialized to a default value between 0 and 1 , set in the user interface. Uncertainties are set to a value of 1.0 in case of a negative (left-hand) or positive (right-hand) experience resulting from a particular norm, and return to the default value in the next time step.

An individual joins a reference group when its average opinion on the group's norms exceeds a threshold $\tau$ and if the individual satisfies the membership conditions. An individual leaves when its average opinion is less than $1-\tau$ and satisfies the conditions to leave, or when it no longer satisfies the membership conditions.

In elections, individuals vote so that they minimize the Manhattan distance between a party's and their own opinion vectors. Then, in the policy process, policies are installed or changed when the average opinion of parties, weighed by the number of votes, exceeds a threshold, set in the user interface.

A reference group adopts a new norm when the average opinion of its members about the norm exceeds the threshold $\tau$ that can be set in the user interface. A 

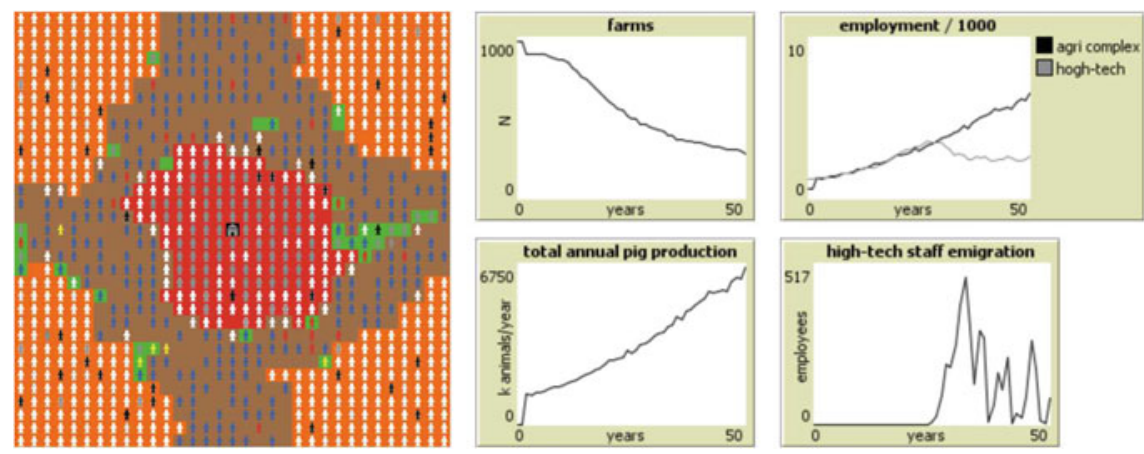

Fig. 10.4 Outcomes from a run without regional livestock policies (legend: see Fig. 10.3)

reference group rejects a current norm when the average opinion of its members about the norm is less than $1-\tau$.

\section{Examples: Disconnect and Reconnect as Stylized Trends}

Figure 10.4 depicts outcomes from a default run, where no regional policies are applied to regulate livestock farming. A spatial planning policy is in place to enable the housing of immigrating employees of the agricultural complex and the high-tech industry by expropriating farmers and expanding city and village areas. Furthermore, external policies increase pig production cost by environmental, animal welfare, and quality regulations. The outcome of this scenario is an economy dominated by the agricultural complex, with a strong increase of export-directed livestock production, disconnected from the city, with serious environmental effects and problems to fulfill staff requirements from the high-tech industry.

The situation depicted in Fig. 10.4 is counterfactual. Policies at the regional level, restricting the location of farms and growth of the livestock, have been in effect since the second half of the 1980s. Currently, additional measures are demanded by several lobbies and pressure groups and particular policies are being discussed to further restrict the livestock industry in Noord-Brabant. As analyzed by Termeer et al. [6], the institutions simulated in the present model are at work and reduce the influence from the agri-complex on regional politics.

Figure 10.5 presents an example of outcomes from a simulation where the institutions of the polity are in effect and reconnect city and countryside. In the first decades, livestock and the high-tech are both growing, while the livestock lobby dominates the politics. Environmental pressure increases and makes the growing population more susceptible to the social responsibility lobbies. Together with the high-tech lobby, they put pressure on political parties and enforce a policy to buy-out farms near populated areas. When pig production grows again due to increasing farm size, 

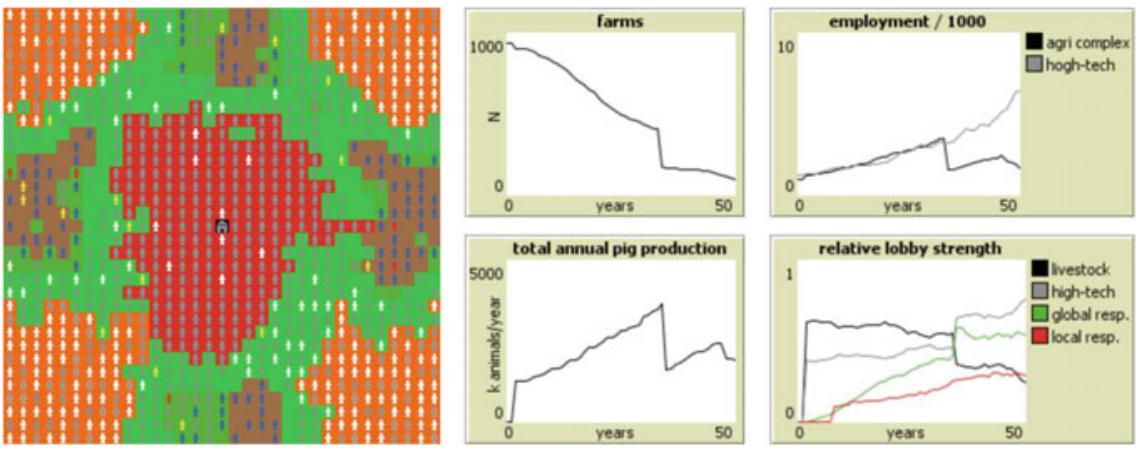

Fig. 10.5 Outcomes from a run where a democratic multi-party polity realizes feedback

a more restrictive licensing policy is enforced by the now powerful social responsibility lobbies. As a result, employment in the livestock industry declines and its influence on politics decreases further. The example shows how institutions matter to keep city and countryside connected.

\section{Conclusion}

Model concepts From an ontological point of view, the ambition of this model is to find a middle ground between, on the one hand, "artificial sociality" models that center on relational processes, and on the other hand, economic models that have simple utility-maximizing agents. We attempted to construct an institutional/political world. We believe that we struck a workable balance between ontological simplicity and plausibility. The combined use of reference groups, lobbies and political parties has potential and can serve as a canvas for other simulations. The model would allow for improvements on the "artificial sociality" side, for instance, by varying the strength of certain reference groups, or by basing voting behavior more on reference group membership and less on opinions.

Validation For a model of this kind, validation is a thorny issue. It implements ideas from institutional economics in an eclectic way, since no theory offers clear guidance; the theories were not invented for that purpose. This means that the model cannot be "validated against theory". On the other hand, it is too stylized to exactly represent the province of Noord-Brabant that served as its source of inspiration and calibration. We therefore aim for no more than face validation based on second-order effects in the simulation. Considered from this perspective the model performs well. The actual state of Noord-Brabant is marked by the pressures shown in Fig. 10.4, where the disconnected livestock industry prevails, Fig. 10.5, where the reconnect is being realized through the institutions of a democratic polity. 
In line with the above, the purpose of this model cannot be to predict, nor even to closely "backcast" what has already happened. Instead it is an illustration of the main issues driving the economic history of the system. It can serve as a boundary object to inform policy, to be used in imagining various futures for the region. It can be useful, provided it is not used out of context or with too many validity claims [2].

\section{References}

1. G.S. Cumming, A. Buerkert, E.M. Hoffmann, E. Schlecht, S. von Cramon-Taubadel, T. Tscharntke, Implications of agricultural transitions and urbanization for ecosystem services. Nature 515, 50-57 (2014)

2. B. Edmonds, R. Meyer (eds.), Simulating social complexity: a handbook (Springer, Heidelberg, 2017)

3. V. Grimm, U. Berge, D.L. DeAngelis. D.L., Polhill, J.G., Giske, J., Railsback, The ODD protocol: A review and first update. Ecological Modelling 221, 2760-2068 (2011)

4. R. Hegselmann, U. Krause, Opinion dynamics and bounded confidence: models, analysis and simulation. J. Artif. Soc. Social Simulation 5(3), 2 (2002). http://jasss.soc.surrey.ac.uk/5/3/2. html

5. J.G. March, A primer on decision making: how decisions happen (Free Press, New York, 1994)

6. C.J.A.M. Termeer, P.H. Feindt, T.D. Karpouzoglou, K.J. Poppe, G.J. Hofstede, K. Kramer, L. Ge, E. Mathijs, M.P.M. Meuwissen, Institutions and the resilience of biobased production systems: the historical case of livestock intensification in the Netherlands. Ecology and Society 24(4), 15 (2019). https://doi.org/10.5751/ES-11206-240415 